\title{
Research on Management Mode Innovation of University Graduate Students under the New Situation
}

\author{
Zhiying Wang \\ College of Life Science, Jilin Agricultural University, Jilin Province, China \\ hust2011xu@126.com
}

\begin{abstract}
Keywords: Management mode; Mode innovation; University graduate students; Management mechanism; Model construction
\end{abstract}

\begin{abstract}
College graduate management mechanism is the system guarantee to cultivate high-quality creative talents, is the key link in the management system of colleges and universities. In recent years, with the number of college graduate enrollment continues to grow, the traditional graduate management system in the mode of management of insufficient attention, the old management mode and management system is not perfect and so on a series of problems have become increasingly prominent, cannot adapt to the objective reality of cultivation education, graduate education, which hinders the realization of quality objectives the. Therefore, in the new situation, actively explore a adapt to the development of the situation to meet the characteristics of graduate management, not only can provide scientific basis and theoretical support for the postgraduate management mechanism, but also can promote the postgraduate management mechanism on the road of innovation.
\end{abstract}

\section{Introduction}

College graduate management mechanism is the system guarantee to cultivate high-quality creative talents, is the key link in the management system of colleges and universities. In recent years, with the continuous growth of the number of graduate students, the cause of China's graduate education has entered a new historical development period. Under this kind of situation, the traditional university graduate student management system mode has been unable to adapt to the objective reality of the graduate education and the training work. Therefore, how to improve the graduate management mechanism, to explore a way to adapt to the development of the situation in line with the characteristics of graduate management, become the key issues facing the management mechanism of graduate students.

The research team growing today, graduate increased indicates that generally promote the education of our country level, also witnessed people for education to enhance the self-balancing ability, education needs to be improved to support, in today's high-tech progress situation, graduate team grow that we need more power to cooperate the work for the graduate management system innovation is essential, but also the continuous research and exploration, how to ensure the graduate academic progress at the same time, let them have more ability to adapt to society, social change, all is the bounden duty of college. College graduate in the work also occupies a very important position, graduate students have the sense of innovation is not only in conformity with the characteristics of the times, but also in line with their skills needs of graduate students, allowing them to practice the adaptability in this rapidly changing market conditions, and made some achievements.

\section{The Main Problems Existing in the Management System of Graduate Students}

Emerging logistics park development model in a certain extent that is emerging logistics park construction and development goals, in the logistics industry to establish new logistics park and select the corresponding mode guarantee their development is to promote the rapid development of the emerging logistics park, enhance its social contribution, achieve the economic goals of the emerging logistics park, social goals and environmental goals. 
Graduate Management Work Is Not Enough Attention. In recent years, the management focus is on undergraduate education, compared to the graduate management work seriously enough, the result is often not clear division of labor, equipment management personnel, and even the lack of full-time teachers, graduate management fees by the lack of investment, management and policy to undergraduate education, the on the daily management of the workload is relatively large [1].

Graduate Management Mode Is Single. Graduate thought more mature, independent and strong, has a comparatively mature outlook on life and world view, therefore, for graduate management should be the management methods and pay attention to diversification, scientific management needs to be strengthened. However, the current graduate management method in management thinking is still in the undergraduate management mode, the use of relatively simple means, and not according to the characteristics of graduate students, follow the subject type management, usually constrained more management than service management, to study simple management and closed [2].

Graduate Management System Is Not Perfect. With the continuous enrollment of graduate students, the management of graduate students in colleges and universities has not kept pace with the needs of the development of the situation in terms of system and mechanism. The management system is mainly composed of rules, it restrains the random behavior and opportunism behavior may occur in interpersonal communication, the system of the community as a total, and always depends on a certain punishment to implement system for people to achieve their personal and group interests and their goal orientation has great influence. At present, most of the postgraduate management also implemented a simple decentralized model, the management responsibility is not clear, the various departments exist the phenomenon of poor communication. For example, graduate school is responsible for the management of graduate students, academic institutions responsible for the teaching management of graduate students, teachers in charge of research and development of scientific research capacity and ideological and moral character. It is difficult to form a system, which is difficult to form a system, and it is easy to cause the form doctrine, thus affecting the overall quality of graduate education [3-4].

\section{The Way of Innovation of Graduate Management System}

College graduate training is to cultivate innovative talents, all the management activities related to this should also be used for the purpose of this study requires students management work to improve the quality and efficiency of postgraduate education management for the purpose of effectively guiding graduate education management practice. Graduate management to achieve success, change

The educational environment of the graduate students is the key, only to provide a free and easy environment for the graduate students to inspire the innovation awareness and ability of the graduate students [5-6].

Actively Create a Relaxed Atmosphere of Cultural Innovation. In higher education, the important significance of the university is nothing more than a certain cultural value and a certain spiritual quality, thus ensuring the vitality of colleges and universities. An important characteristic of university culture is to have diverse disciplines, subject diversification also allows students to different degrees to receive a good education, so that they have different ways of thinking, cognition and behavior characteristics. All of these differences are explained by the flexible and changeable of the higher education. For this, the university should create a relaxed atmosphere for the campus, let them in a relaxed and happy environment for all kinds of studies. At the same time, it can make the exchange of students between different ages more smoothly. Because the innovation ability is in a relaxed and pleasant environment, the creation of this relaxed cultural environment, is conducive to the students to fully divergent thinking, but also conducive to the creation of their various innovative ability. At the same time, relaxed and pleasant atmosphere also determines whether a research can be carried out smoothly, if in a pleasant and relaxing environment, it is easy to form a research atmosphere, it can stimulate the innovation ability.

Create Personalized Management Space. The management needs of humanity, but also need personalized humanized implementation in which is mainly because of the different ways of thinking 
and behavior of graduate students have different characteristics, their differences also determines their personality differences, therefore, colleges and universities during the postgraduate research work innovation tube time, consideration should be given to the study students individual differences, to avoid similar treatment. First, we should create a personalized space in education, and the competition between universities makes education has its own individuality, and pay attention to building the personalized space in the quality, whether it is academic features, style characteristics and educational characteristics, should possess different personalized way; secondly tutor personalized, that is to say different teacher research in a certain field all have different research results and practical guidance, therefore, when the student guidance should also exhibit personalized full space, lets the student feel out of the ordinary personalized guidance brought by students; again the design of personalized era, decided the moment is a full of competition in the 1990s, each individual graduates have different ways of thinking and approach to treat the problem, therefore, graduate students should fully express their own out of the ordinary, express their own various interests, characteristics, skills and ambition, therefore, the graduate student individual should be designed to meet their own requirements of the acts of fashion, will humanization as a code of conduct, design behavior in line with modern needs.

The Scientific, Modernization and Internationalization of Graduate Education. Graduate education at a high level because of this stage, not when education like other levels of students and learning is just simple to teach, but should create a high-level space. This requires colleges and universities should pay attention to the scientific, modern and international education of graduate education. One is the focus on the integration of scientific way in education, guidance in the high-tech information age way of students, leading the education scientific education, scientific research personnel with high level of demand; the two is education should be oriented to modernization, fully combined with the current national conditions, focus on the modernization in teaching methods, abandon any obsolete the teaching mode to modern education modernization as the criterion, guide graduate work; three is education should also realize the internationalization, namely tendency of teachers in teaching content and graduate students in the exchange process should have international. The teacher is an important knowledge source of students, teachers should open student's vision assurance, universities can employ foreign excellent interaction between the teachers and graduate students, and constantly optimize the allocation of new resources, ensure the internationalization of education mode.

Strengthen the Construction of the Tutor Team. The cultivation of graduate students is an organic combination of educational management and academic activities. The cultivation mode of graduate students is mainly the responsibility system of teachers. In this way, it is beneficial for the tutor to grasp the academic trends of the graduate students in real time. Strengthen academic exchanges between teachers and students. Therefore, to improve the quality of postgraduate training, a comprehensive quality of the tutor is very important. With the development of graduate education and training, the tutor of graduate requirements are increasingly high, a good teacher should not only guide the graduate to learning the professional knowledge, but also to guide the graduate research practice, graduation thesis, but also to guide the graduate students to learn, to guide the healthy development of students personality and character. Therefore, to establish and perfect the mechanism of the tutor team, promote the construction of the system of tutor development. Including a combination of tutor's selection, training, appointment, tenure assessment, dismissal and a series of rules and regulations, improve the enthusiasm of teachers training of graduate students and graduate students of the guidance force. Set up a series of scientific evaluation mechanism, incentive and restraint mechanism. In order to improve the quality of postgraduate training, promote the cultivation of innovative talents, the teacher's words and deeds plays a leading role, at the same time, graduate and postgraduate departments are the specific institutions for teaching and scientific research work, has the function of administrative management of graduate students, to improve the graduate training quality, not only to play teach the role of teachers, but also to play a guiding role in the cultivation of faculty and graduate students at the management function. The management of postgraduate in humanized management under the principle of rigid type management, to provide graduate students creativity free academic environment, 
management, straighten out the relationship between tutors and graduate students, and continuously explore and innovate.

\section{Summary}

With the relaxation of college enrollment, enrollment conditions and admission threshold lowered levels of diversity in graduate school, a graduate with age, resulting in a lack of communication between different levels, different ages, due to the lack of communication of non-graduate students, cannot working together to study, so for dependence of the collective is low, management is not able to form a cohesive force, the management of graduate students in the low and complex state. These complex conditions make the graduate management confusion, which involves the innovation of the problem cannot be solved together, thus leading to the lack of innovation ability. Through the research and investigation of a series of graduate students is not difficult to find the lack of certain guidance in education, in teaching because of tutor's configuration is not reasonable, plus some limited conditions, resulting in the development of the graduate development is blocked, not to mention the way of innovation. Innovation is one of the important ways of colleges and universities, is the development of the students, cultivate the key way of students, for graduate students, must solve the graduate management, ensure postgraduate work smoothly into the study on innovation mode of management, promote and enhance the graduate student management work.

In summary, there are many deficiencies in graduate management, these deficiencies are the lack of graduate management. Therefore, the university must be combined with the current characteristics of the times, innovation management mechanism according to the individual differences of graduate students, graduate students to make the management more efficient, innovative and personalized, promote the innovation mechanism of the management of graduate students in the effective and efficient operation.

\section{References}

[1] Pascarella, E.T.\& Terenzizi P.T. How College Affects Students: A Third Decade of Research. San Francisco: Jossey-Bass, 2005.

[2] National Survey of Student Engagement. Major differences: Examining student engagement by field of study results. Bloomington, IN: Indiana University Center for Postsecondary Research, 2010.

[3] Azza Karam. Transnational political Islam: globalization, ideology and power. London, sterling, Pluto Press, 2004.

[4] Hoover, Kenneth R., Economics as ideology: Keynes, Laski, Hayek, and the creation of contemporary politics. Rowman \& Littlefield, 2003.

[5] John Storey. Cultural Studies and the Study of Popular Culture: Theories and Methods. University of Georgia Press, 2010.

[6] Williams Raymond. The Sociology of Culture. New York: Schocken Books, 2002. 